\title{
Problemas de aplicación de la cláusula de prevalencia del Derecho del Estado
}

\author{
Casimiro López García \\ Interventor-Tesorero de Administración Local
}

Sumario: I. EL PRINCIPIO DISPOSITIVO EN LA CONSTITUCION ESPAÑOLA DE 1.978 Y LA CLÁUSULA DE PREVALENCIA DEL DERECHO ESTATAL.-II. MATERIAS Y COMPETENCIAS CONCURRENTES Y COMPARTIDAS EN LA CE DE 1978III. PREPONDERANCIA DE LAS COMPETENCIAS COMPARTIDAS EN LA CE.IV. CONCEPTO Y EVOLUCIÓN DE LA LEGISLACIÓN BÁSICA. 4.1. Concepto material y formal de bases. 4.2. Evolución.-V. LA CUESTIÓN DE LA «LEX REPETITA»EN LA LEGISLACIÓN DE LAS CCAA.-VI. LA CLÁUSULA DE PREVALENCIA DEL DERECHO DEL ESTADO: SU ALCANCE Y SIGNIFICADO. 6.1. Controversia conceptual. 6.2. Alcance del principio de prevalencia en CE de 1978. 6.3. La Cuestión del «mayor valor» del derecho Estatal. 6.4. La cláusula de prevalencia y las relaciones entre las normas básicas y la legislación de desarrollo de las CCAA.- - VII. LA OPERATIVIDAD DE LA CLÁUSULA DE PREVALENCIA EN LA JURISPRUDENCIA CONSTITUCIONAL: LOS VOTOS PARTICULARES A LA STC 1/03 y 178/2004. 7.1. Cláusula de prevalencia e igualdad en el ejercicio de derechos. 7.2. Cláusula de prevalencia y legislación básica. 7.3. La doctrina de la STC 178/2004.-VIII. NECESARIA DOCTRINA CONSTITUCIONAL PREVIA. 8.1. La cláusula de prevalencia y los tribunales ordinarios.-IX. VALORACIÓN FINAL.

\section{EL PRINCIPIO DISPOSITIVO EN LA CONSTITUCION ESPAÑOLA DE 1978 Y LA CLÁUSULA DE PREVALENCIA DEL DERECHO ESTATAL}

La Constitución Española de 1.978 (CE), por influencia directa de la Constitución republicana de 1931, posibilita la constitución de entes territoriales de naturaleza política - Comunidades Autónomas- (CCAA), que pueden asumir competencias legislativas plenas en numerosas materias. La CE no establece $^{1}$ las acostumbradas listas cerradas de competencias del Estado y de los estados federados (CCAA); por el contrario, la autonomía se configura como un «derecho» de las nacionalidades y regiones de acceso al autogobierno (artículos. 2, 143.1 y 151 y disposición transitoria $2^{\mathbf{a}}$ ), que se concreta en un

\footnotetext{
${ }^{1}$ Una parte de la doctrina ha visto en la existencia de estos dos ordenamientos separados y unidos en el vértice constitucional, que también reparte los distintos papeles que corresponden al Estatal y a los Comunitarios, la conocida llamada doctrina de los «tres grados» establecida por Kelsen y Nawiasky para explicar el Estado Federal, que no estaría conformado por dos niveles de poder, sino por tres el de los Estados miembros (Gliedstaaten) el del Estado superior (Oberstaat) y el del Estado global (Gesamtstaat), que se superpondría a los otros dos como un nivel propio.
} 
«Estatuto de Autonomía», verdadera norma institucional de cada Comunidad, que establece la organización y relaciona las competencias que, «dentro del marco establecido en la Constitución», asume cada Comunidad (art. 147.1) ${ }^{2}$.

Se establece así el denominado «principio dispositivo» en materia de la determinación de los niveles de autogobierno de las nacionalidades y regiones, configurándose un sistema de distribución territorial abierto ${ }^{3}$, que a pesar de los sucesivos intentos de generalización y homologación no ha conseguido plasmar un modelo único, ni siquiera para las denominadas históricas: Cataluña, País Vasco y Galicia. En consecuencia, una de las diferencias teóricas más importantes entre el Estado Federal y el Estado de las Autonomías reside en este principio dispositivo de la $\mathrm{CE}$, que no distribuye directamente las competencias entre el Estado y las CCAA, limitándose a presentar un marco formal en el que las Comunidades que se constituyan podrán asumir competencias. Por ende, treinta años después de la elección de las Cortes Constituyentes, se ha consolidado un sistema territorial que resiste todo intento de cierre y de homologación de las distintas CCAA, que tienden a asumir como exclusivas todas y cada una de las competencias de desarrollo legislativo que figuran en sus Estatutos, en un intento de escapar a las competencias del Estado para formular la legislación básica de las distintas materias que figuran en distintos apartados del artículo 149.1 de la CE y de la formulación de condiciones básicas o el ejercicio de los poderes de coordinación que reservan al Estado las cláusulas $1^{\mathrm{a}}, 11^{\mathrm{a}}$ y $13^{\mathrm{a}}$ del mismo artículo 149.1. CE; al mismo tiempo que se eluden los posibles efectos de la cláusula de prevalencia del derecho del Estado que figura, cerrando el sistema de distribución competencial, en el artículo 149.3 CE, con un reconocimiento expreso de la prevalencia de las normas del Estado, en caso de conflicto, sobre las de las CCAA en todo lo que no esté atribuido a la exclusiva competencia de éstas. Determinar así qué competencias comunitarias tienen naturaleza exclusiva y, especialmente, si la legislación de desarrollo de las bases es o puede calificarse de competencia exclusiva es una de las cuestiones trascendentales del denominado Estado de las Autonomías.

\section{MATERIAS Y COMPETENCIAS CONCURRENTES Y COMPARTIDAS EN LA CE DE 1978}

A la hora de clasificar las competencias, la doctrina distingue entre competencias exclusivas, concurrentes y compartidas; se entienden exclusivas cuando todas las facultades sobre una misma materia se atribuyen a una sola entidad (Estado o CCAA), en cierto sentido, se identifica materia y compe-

\footnotetext{
${ }^{2}$ Esto es lo que se ha llamado el «carácter dispositivo» de la autonomía territorial en nuestra Constitución, la cual no diseña ni el «mapa autonómico», esto es, la división del territorio nacional en un número determinado de Comunidades Autónomas, ni el contenido concreto de la autonomía, el cual deberá ser «asumido», dentro del cuadro ofrecido por la Constitución, a través del respectivo Estatuto.

${ }^{3}$ Se ha dicho que está definido por la nota «in fieri».
} 
PROBLEMAS DE APLICACIÓN DE LA CLÁUSULA DE PREVALENCIA DEL DERECHO DEL ESTADO

tencia; se habla de competencias concurrentes, cuando la legislación básica corresponde al Estado y su desarrollo normativo a las $\mathrm{CCAA}^{4}$. La concurrencia normativa no es un concepto pacífico, un sector doctrinal entiende que lo compartido es la materia, sobre la que, de hecho se atribuyen verdaderas competencias exclusivas de una y otra parte (E. Aja); en un intento de racionalizar los distintos conceptos, la competencia exclusiva en el sistema de la CE de 1978 queda limitada a los supuestos en que el Estado o la Autonomía disponen totalmente de la materia y sobre ella ejerce todas las potestades legislativas y ejecutivas -o sobre una parte determinada de una materia-; por el contrario, estaremos ante competencias compartidas cuando el Estado o las CCAA pueden utilizar un tipo determinado de potestades -legislativas o ejecutivas - tanto cuando se comparte una materia como cuando se comparten potestades de una misma calidad, ya sea la legislación o la ejecución sobre la misma materia ${ }^{5}$.

La distribución competencial de la CE 78 sigue siendo una cuestión controvertida, que no termina de superar la resistencia de un modelo de Estado «sui generis» que no se identifica con los ejemplos del Estado Regional ni con el Federal. Para mayor confusión, esta falta de un modelo claro se complica más, al mezclar la CE los conceptos de materia y de competencia ${ }^{6}$. La materia o materias serían el objeto de la competencia, mientras que la competencia hace referencia a la titularidad de un poder jurídico: «la titularidad de una potestad o función pública sobre una materia determinada» (A. Blasco). La competencia es la medida de poder político de un ente público; tener competencia es contar con la atribución específica de potestades o funciones en relación con una determinada materia u objeto ${ }^{7}$. Su contenido - potestades o funciones que se le atribuyen-y el objeto de tales poderes $\mathrm{y}$ facultades que sería la propia materia ${ }^{8}$. Lo que aconseja separar convenientemente la lista de las materias de la de atribución de competencias; distinción y separación que, precisamente, no concurren en la CE 78, al aplicar una concentración de técnicas en su sistema de reparto entre el Estado y las CCA que resulta de muy difícil aplicación (Muñoz Machado) ${ }^{9}$. En definitiva, la

\footnotetext{
${ }^{4}$ E. García de EnTERría (1990), Curso de Derecho Administrativo, 5ª ed., 302 págs. Editorial Cívitas, Madrid.

${ }^{5}$ Enrique Álvarez Conde (1993), Curso de derecho constitucional. Ed. Tecnos, Madrid.

${ }^{6}$ Para la doctrina Italiana, el concepto de materia está referido a un conjunto de actividades, bienes o instituciones propiamente jurídicas referentes a un sector homogéneo. Materia sería así la realidad objetiva sobre la que se ejercen las competencias.

${ }^{7}$ La STC. 123/1984, de 18 de diciembre, configura la materia como un «conjunto de actividades, funciones e institutos jurídicos relativos a un sector de la vida social». Es decir, continúa la elaboración doctrinal apuntada, reconociendo, en la Sentencia 125/1984, de 20 de diciembre, que el concepto materia se refiere a una parte de la realidad social o a sectores jurídicos diferenciados o aspectos financieros propiamente dichos.

${ }^{8}$ Como se ha señalado desde otros sectores doctrinales (E. Aja), el concepto de competencia comprende la función, la materia y el tipo de intervención pública que haya de producirse.

${ }^{9}$ El artículo 148.1 CE contiene una lista de materias, no una lista de competencias. Y el artículo 149.1 contiene tanto una lista de materias como una lista de competencias.
} 
materia puede estar o no atribuida en bloque, pero el hecho de que esté compartida la materia no quiere decir que lo esté la competencia ${ }^{10}$; sin olvidar que sobre la mima materia se entrecruzan títulos distintos y opuestos, unos específicos y otros generales u horizontales.

En esta confusión, la cláusula de prevalencia del Derecho estatal del artículo 149.3 CE que, por su propia posición sistemática y su literalidad, debiera reconocérsele una función de cláusula de cierre del sistema, tampoco ha encontrado una respuesta unánime en la doctrina y muy escasa aplicación práctica. Para algunos (L. Parejo), es una auténtica cláusula de atribución de competencia; para otros, no altera el régimen constitucional de reparto de competencias, pero es una verdadera norma de conflicto que otorga preferencia a la legislación básica del Estado sobre la de desarrollo de las CCAA a la que viene a desplazar en los supuestos de superposición o concurrencia de títulos (Enterría); no faltan quienes le atribuyen un papel muy limitado a la hora de resolver los conflictos de competencias legislativas compartidas o entrecruzamiento de títulos competenciales sobre materias compartidas ${ }^{11}$; para esta interpretación, la prevalencia del derecho estatal no es un título oponible a las competencias exclusivas de las CCAA; en cuanto a la doctrina constitucional, hasta fechas recientes ha evitado su aplicación a los conflictos surgidos entre legislación básica del Estado y legislación de desarrollo por las CCAA, cuando constituyen en abstracto su verdadero campo de aplicación.

El TC se ha mostrado reacio a la aplicación de la cláusula de prevalencia del derecho estatal en la resolución de los conflictos de competencias o conflictos normativos entre la legislación básica del Estado de los distintos números del artículo 149.1 CE y la correspondiente legislación de desarrollo de las CCAA. Ha preferido resolver los recursos en materia de legislación de bases del Estado versus legislación de desarrollo de las CCAA a tenor de la regla de la competencia, atribuyendo en exclusiva la formulación de las bases al Estado y a las CCAA el desarrollo de sus propias políticas legislativas. A resultas de esta práctica, se ha visto obligado a establecer una extensa y complicada doctrina sobre el alcance de las competencias exclusivas del Estado y sobre los requisitos formales y materiales para formular las «bases» de cada materia, y sobre el alcance y la naturaleza de las competencias exclusivas de las CCAA para establecer su desarrollo legislativo. En el fondo, se trataba de evitar que una interpretación extensiva del mayor valor del derecho estatal terminase por degradar las leyes de las CCAA a meras normas reglamentarias.

De acuerdo con esta doctrina y esta praxis de la justicia constitucional, antes de entrar en el análisis de la cláusula de prevalencia, resulta imprescindible

\footnotetext{
${ }^{10}$ E. GARCÍA DE ENTERRía, Opus cit num 5. Entiende que la exclusividad implica la exclusión: no habrá exclusividad y sí colaboración cuando se reparte la regulación de la materia entre bases y desarrollo, o cuando hay separación entre legislación y ejecución.

11 Jesús Leguina Villa, «Notas sobre los principios de competencia y prevalencia en la legislación compartida». REALA, número 258, abril-junio de 1993.
} 
PROBLEMAS DE APLICACIÓN DE LA CLÁUSULA DE PREVALENCIA DEL DERECHO DEL ESTADO

delimitar el alcance del concepto competencia exclusiva en la CE, más cuando los Estatutos de Autonomía asumen todas las competencias posibles - las últimas reformas, enmendando la doctrina constitucional-calificándolas siempre de exclusivas, o como la reforma del Estatuto Catalán por Ley Orgánica 6/2006, dedicando todo un capítulo (artículos 111 a 113) a la definición de los términos materia y competencia y su alcance ${ }^{12}$. Este modus operandi ha obligado al Tribunal Constitucional, desde los primeros momentos, a reinterpretar muchos preceptos estatutarios matizando la exclusividad de las competencias estatutarias y declarando «el sentido marcadamente equívoco con que el adjetivo "exclusivo» se utiliza en la Constitución y en los Estatutos» (SSTC de 16 de noviembre de 1981 y 5/1982, de 8 de febrero) ${ }^{13}$, entre otras. De acuerdo con esta doctrina, no es fácil determinar «a priori» el alcance del concepto competencia exclusiva cuando nos referimos a la legislación de desarrollo normativo sobre las bases establecidas por Ley del Estado, ni establecer con seguridad la frontera competencial entre los que se deba entender por básico y lo que pueda entenderse por desarrollo normativo y, en definitiva, identificar las posibles situaciones de conflicto que permitan aplicar la regla de la prevalencia.

\section{PREPONDERANCIA DE LAS COMPETENCIAS COMPARTIDAS EN LA CE}

Los sistemas de distribución de competencias de los estados compuestos, en particular la distribución de competencias en los estados federales, se atienen a dos patrones básicos: el de distribución horizontal y el de distribución vertical. Según el criterio de distribución horizontal, la competencia se reparte atendiendo a la materia de que se trate; de acuerdo con el criterio vertical, el reparto de competencias está a la actividad legislativa o ejecutiva que puede desarrollar cada uno de las partes ${ }^{14}$. En un primer análisis de la distribución

\footnotetext{
${ }^{12}$ Lo que, salvo mejor opinión, está reservado al Poder Constituyente, STC 76/83.

13 STC 5/82 FJ 1: «...Este Tribunal ya ha advertido, en efecto, sobre el sentido marcadamente equívoco con que el adjetivo "exclusivo" se utiliza tanto en el texto de la Constitución como en el de los Estatutos de Autonomía (sentencia de 16 de noviembre de 1981, en recurso de inconstitucionalidad número 184/1981, "Boletín Oficial del Estado" de 28 de noviembre de 1981, suplemento, página 2; y, en consecuencia, resulta aventurado cualquier razonamiento que, como el del presente caso, intente arrancar de la diferencia existente entre una competencia atribuida con carácter exclusivo, sin perjuicio de la legislación básica que corresponde al Estado, y una competencia para legislar y ejecutar que debe ejercerse «en el marco de la legislación básica del Estado y, en su caso, en los términos que la misma establezca». Estas diferencias de dicción autorizan a entender, entre otras consecuencias, que cuando se utiliza esta segunda fórmula se intenta sujetar más estrechamente la competencia legislativa comunitaria al marco de la legislación básica del Estado, pero en modo alguno a sostener que se ha privado con ello a la Comunidad Autónoma de su facultad de legislar hasta que sea habilitada para ello por una Ley estatal, pues esto equivaldría una vez. más a equiparar legislación básica con Leyes marco, tesis ya rechazada explícitamente por este Tribunal (cf. sentencia antes citada de 28 de julio de 1981).

14 BAssols ComA, «El artículo 149 de la constitución en relación con el artículo 150.2: Análisis de la delegación en materia de competencias estatales exclusivas». RAP, ním. 97, enero-abril de 1982,
} 
de competencias en la Constitución española de 1978, se advierte un sistema de doble lista: la primera puede verse en el artículo 148.1 de la Constitución que, considerado por la doctrina como una verdadera disposición transitoria $^{15}$, enumera las materias en las que podrían asumir competencias exclusivas las comunidades autónomas; la segunda estaría evidentemente en el artículo 149.1, que relaciona las materias en las que el Estado tiene competencia exclusiva. Sin embargo, una lectura más profunda y atenta ilustra que el único artículo verdaderamente decisivo para el reparto competencial es el 149.1 que, siguiendo el precedente de la Constitución española de $1931^{16}$, establece un sistema de reparto horizontal de competencias con una sola lista que parece tener una clara influencia de los sistemas federales. Las competencias exclusivas solo se asignan cuando se atribuye la materia en bloque. En el resto de los casos, tanto cuando se atribuyen sectores de una materia como un determinado tipo o calidad de potestades, se trata de competencias compartidas, entre las que destacan, por su número e importancia, las que reservan al Estado la competencia legislativa para establecer las bases o la legislación básica de una materia, y autorizan un desarrollo normativo por las CCAA que así lo asuman en sus respectivos estatutos ${ }^{17}$.

El núcleo de esta «concurrencia» legislativa está constituido por aquellas materias en las que, de modo expreso, el Estado se reserva la legislación básica, correspondiendo a las Comunidades Autónomas el desarrollo normativo de dicha legislación básica, bases o normas básicas o condiciones básicas ${ }^{18}$.

pág. 32: Si se utiliza el criterio horizontal, la distribución de competencias puede seguir el llamado sistema de lista única o el sistema de doble lista. Por el procedimiento de lista única cabe, a su vez, una de estas dos posibles soluciones: el sistema federal, en el que sólo se enumeran las funciones atribuidas a la Federación, dejando el resto a los Estados; o el sistema regional, en el que las funciones se atribuyen a las regiones dejando el resto al Estado. El procedimiento de lista doble no hace sino distribuir competencias por razón de la materia, atribuyéndolas tanto al Estado como a las Comunidades Autónomas, según los casos. Pero una distribución de competencias basada exclusivamente en un criterio horizontal sería incompleta y poco precisa; el criterio vertical sirve así para saber qué actividad sobre una materia concreta está atribuida a cierto ente u órgano. Esta determinación por el criterio vertical puede venir establecida en el sistema de una o de doble lista, pues en estos casos, además de establecerse la materia sobre la que tiene la competencia, nada impide que se establezca la naturaleza de la actividad. Sin embargo, la combinación del criterio horizontal con el vertical suele venir determinado con una mayor claridad del sistema denominado de tres listas. Según este sistema se establece la competencia exclusiva de cada uno de los entes, y una tercera lista señala las competencias que sobre una misma actividad han de ser consideradas como concurrentes. Este sistema es el seguido, por ejemplo, por el artículo 74 de la Constitución alemana, y tiene un gran predicamento en la doctrina.

${ }^{15}$ L. Cosculluela Montaner, La determinación constitucional de las competencias de las CCAA, en la Constitución Española y las Fuentes del Derecho. IEF. Madrid, 1979.

16 Artículos 14 a 16, influenciados por la Constitución Alemana de Weimar, de 1919.

17 E. García DE ENTERRÍA, Opus cit num 5, las denomina competencias concurrentes, que suponen una aplicación efectiva de las técnicas de cooperación del Federalismo Cooperativo.

18 Términos que no son homogéneos, como ha declarado el TC, el concepto de «bases» es más amplio que el de «legislación básica», ya que mientras en este último caso las potestades que se atribuyen son ordinariamente normativas, en el supuesto primero pueden estar incluidas normalmente potestades ejecutivas. Sentencias de 28 de enero de 1982, 7 y 28 de abril de 1983, 20 de mayo de 1983 y, especialmente, la de 28 de junio de 1983, y las condiciones básicas se refieren a la potestad del Estado para enmarcar la legislación comunitaria en aras del igual ejercicio de derechos. 
Como ha retirado la doctrina ${ }^{19}$ y ha reconocido el Tribunal Constitucional, en materia de reparto constitucional de competencias en la CE 78, el supuesto mayoritario es el de competencias compartidas. La preponderancia de las competencias legislativas del Estado se afianza en la relación legislación básica-legislación de desarrollo o, en otros supuestos, por la aplicación de los principios o cláusulas derivadas de la garantía de la unidad de mercado, de la propia unidad del ordenamiento jurídico o de la necesaria posición de igualdad de derechos y deberes de todos los ciudadanos, que permiten introducir criterios generales de ordenación estatal sobre las competencias exclusivas de las CCAA o someter éstas a la coordinación y a las directrices del Estado $\left(149.1 .1^{\mathrm{a}}, 11^{\mathrm{a}} \text { y } 13^{\mathrm{a}}\right)^{20}$. Esta concurrencia legislativa de la CE de 1.978 también está directamente influenciada por la Constitución Federal Alemana de 1949 (GARCÍA DE ENTERRÍA), y constituye en el fondo una técnica de colaboración legislativa habitual en los estados compuestos. Por ende, resulta trascendental establecer o determinar el principio jurídico que rige la relación entre las bases estatales y las normas de desarrollo comunitarias en los supuestos de conflicto, sin que la jurisprudencia constitucional consolidada sobre el alcance de la legislación básica haya facilitado, por el momento, una doctrina clara sobre el alcance de la cláusula de prevalencia que, por el contrario, cuenta con pocos y limitados pronunciamientos.

\section{CONCEPTO Y EVOLUCIÓN DE LA LEGISLACIÓN BÁSICA}

El sistema de participación legislativa del Estado y de las CCAA en la regulación de las materias que refiere el artículo $149.1^{\circ} \mathrm{CE}^{21}$, según acredita la experiencia de los sistemas federales europeos - Alemania, Suiza, Austria - y regionales - Italia - (donde se aplica un sistema de leyes generales con alcance teórico similar), supone la técnica constitucional más

\footnotetext{
19 E. García de EnTERría, Opus cit num 5.

${ }^{20}$ Sentencia 196/1988, de 17 de octubre, ha señalado que «la competencia estatal en cuanto a la ordenación general de la economía responde al principio de unidad económica y abarca la definición de las líneas de actuación tendentes a alcanzar los objetivos de política económica global o sectorial fijados por la propia Constitución, así como la adopción de las medidas necesarias para garantizar la realización de las mismas». Por su parte, la Sentencia 75/1989, de 24 de abril, ha insistido en la misma línea señalando que «dentro de la competencia de dirección de la actividad económica general tienen cobijo las normas estatales que fijen las líneas directrices y sus criterios globales de ordenación de sectores económicos concretos, así como las previsiones de acciones o medidas singulares que sean necesarias para alcanzar los fines propuestos dentro de la ordenación de cada sector». En análogo sentido se ha manifestado la Sentencia 145/1989, de 21 de septiembre.

${ }^{21} \mathrm{El}$ artículo 149.1 de la Constitución atribuye competencia exclusiva al Estado para una «regulación
de condiciones básicas» (núm. $10^{\circ}$ ), la formulación de «bases» (núms. $\left.8^{\circ}, 11 .^{\circ}, 13 .^{\circ}, 16 .^{\circ} 18 .^{\circ}, 25 .^{\circ}\right)$, o
para establecer la «legislación básica» (núms. $\left.17 .^{\circ}, 18 .^{\circ}, 23 .^{\circ}\right)$, las «normas básicas» (núms. $27 .^{\circ}, 30 .^{\circ}$ ),
o el «régimen general» (núm. $21 .^{\circ}$ ). Se trata de reservar a favor del Estado la competencia legislativa
básica que no agota la regulación de la respectiva materia, sino que prevé una participación ulterior de
las Comunidades Autónomas en tal regulación mediante las normas que en el mismo artículo 149.1 se
llaman en algún caso (núm. $27 .^{\circ}$ ) normas «de desarrollo», término que ha pasado luego a la generali-
dad de los Estatutos.
} 
importante del sistema autonómico de atribución de competencias; de tal manera que constituye el fundamento de la mayoría de las competencias normativas autonómicas ${ }^{22}$. El sistema de reparto competencial legislación de bases-desarrollo es uno de los fundamentos de la distribución territorial del poder en nuestra Constitución, y a su vez es el producto de los dos centros territoriales de poder político; correspondiendo al Estado la formulación de legislación de bases o básica para establecer «el marco de una política global» (Sentencia constitucional de 4 de noviembre de 1982) sobre la materia de que se trate; a las CCAA su desarrollo, con la libertad suficiente para la definición de políticas propias. En definitiva, la legislación básica es, fundamentalmente, una regulación general y unitaria para todo el Estado ${ }^{23} \mathrm{y}$, como ya expresaba la STC de 28 de abril de 1983, ha de establecer los «elementos normativos uniformes o de denominador común», «mínimo común a todas las Comunidades Autónomas»; consolidándose una doctrina en la que puede verse la influencia de la jurisprudencia constitucional alemana, que también ha formulado una doctrina similar sobre la base de la noción del interés de la Federación, que establece el art. 72.2 de la Ley Fundamental ${ }^{24}$ : El mismo alcance tienen en Italia respecto a las leyes estatales »de principios» previstas en el artículo 117 de su Constitución, con la diferencia importante de concebirse como habilitadoras de la competencia legislativa regional.

\subsection{Concepto material $y$ formal de bases}

El concepto de legislación básica se enfrentó, en las primeras sentencias del TC, a la determinación de sus requisitos formales. Se trataba de esclarecer si la legislación básica estaba o no sujeta al principio de reserva de ley en sentido formal o era un concepto material. En un primer momento, para salvar el grueso de la legislación vigente a la entrada en vigor de la CE y facilitar el ejercicio legislativo de las CCAA sin tener que estar a la previa formulación de las bases por ley del Estado, al modo y manera de las leyes de principios de la Constitución Italiana, se inclinó por un concepto mate-

\footnotetext{
${ }^{22}$ Lo que se puede constatar con el examen de los artículos 113 y siguientes de la LO 6/2006, de Estatuto de Autonomía para Cataluña.

${ }^{23}$ «Lo que la Constitución persigue al conferir a los órganos generales del Estado la competencia exclusiva para establecer las bases de la ordenación de una materia determinada es que tales bases tengan una regulación normativa uniforme y de vigencia en toda la Nación, lo cual asegura, en aras de intereses generales superiores a los de cada Comunidad Autónoma, un común denominador normativo, a partir del cual cada Comunidad, en defensa del propio interés general, podrá establecer las peculiaridades que le convengan» (Sentencias constitucionales de 28 de enero, 8 de julio y 30 de noviembre de 1982).

${ }^{24}$ «La Federación tendrá derecho a legislar en este campo —el de las materias enunciadas en el art. 74- en la medida en que sea necesaria una regulación federal porque: $1 .^{\circ}$ un asunto no pueda ser eficazmente regulado por la legislación de un sólo Land; $2 .^{\circ}$ o porque la regulación de un asunto a través de una Ley de un Land puede interferir los intereses de otro Lana o de la Nación; $3 .^{\circ}$ o, en fin, cuando lo requiera el mantenimiento de la unidad jurídica o económica o de la uniformidad de las condiciones de vida por encima del territorio de un Land.
} 
PROBLEMAS DE APLICACIÓN DE LA CLÁUSULA DE PREVALENCIA DEL DERECHO DEL ESTADO

rial de bases que evitó tanto el citado problema de la previa configuración del marco legislativo autonómico como la derogación implícita de de toda la legislación preconstitucional, siempre con una interpretación favorable a la primacía de la Constitución, que tiene poder derogatorio directo real y efectivo $^{25}$. La temprana Sentencia 1/1982, de 28 de enero ya incorpora este concepto: «De esta noción material de bases se infiere que unas normas no son básicas por el mero hecho de estar contenidas en una ley y ser en ella calificadas como tales (lo cual sería consecuencia lógica de una noción formal de bases), sino que lo esencial del concepto de base es su contenido» ${ }^{26}$. Se admite desde el primer momento su formulación por Real Decreto, aunque se anuncia el principio de preferencia de ley, para terminar reconociendo hasta la participación de actos administrativos concretos, Sentencia de 26 de junio de 1983.

\subsection{Evolución}

El concepto material de bases experimentará en el año 1.998 una clara evolución hacia un concepto formal-material de bases. La entrada en vigor de la nueva legislación promulgada y autodeclarada general y básica: Ley de Reforma de la Función Pública, General de Sanidad, y de otras que sin tal declaración inciden directamente en el ejercicio de las competencias legislativas de las Comunidades Autónomas como la Ley de Bases de Régimen Local, las Leyes de Costas, de Aguas, de Defensa de los Consumidores y Usuarios, y la interposición de continuos recursos de inconstitucionalidad contra esta legislación por las Comunidades Autónomas, obligaron al Tribunal Constitucional a matizar su doctrina sobre la naturaleza y rango legislativo de esta normativa básica o formulación de las bases en la dirección apuntada. A partir de la S. 49/1988, de 22 de marzo, que ya introduce un carácter excepcional al concepto material de bases ${ }^{27}$, el TC evoluciona hacia un concepto formal-material de la normativa básica, que aparece dibujado ya en la Sentencia 69/1988, de 19 de abril: el concepto de bases incluye y tiene que

\footnotetext{
25 STC 4/81, sobre inaplicación por los tribunales de leyes preconstitucionales.

${ }^{26}$ Contenido que ya había sido determinado en la importante Sentencia sobre las Diputaciones catalanas de 28 de julio de 1981. En esta ocasión el Tribunal había señalado: «Por principios, bases y directrices hay que entender los criterios generales de regulación de un sector del ordenamiento jurídico o de una materia jurídica que deben ser comunes a todo el Estado. Por ello, la mencionada idea posee un sentido positivo y otro negativo: el sentido positivo manifiesta los objetivos, fines y orientaciones generales para todo el Estado, exigidos por la unidad del mismo y por la igualdad sustancial de todos sus miembros; en sentido negativo, por la misma razón, constituye el límite dentro del cual tienen que moverse los órganos de las Comunidades Autónomas en el ejercicio de sus competencias cuando, aun definiéndose éstas como exclusivas, la Constitución y el Estatuto las dejan así limitadas».

27 «La calificación como básica de una norma por el legislador no supone por sí misma que esa norma tenga tal carácter, pues el concepto material implica dos requisitos: 1) las bases deben garantizar un mínimo común a todo el territorio, dirigido a asegurar los intereses generales, y 2) las bases pueden comprender regulaciones detalladas en aspectos concretos e incluso pueden incluir la potestad de dictar actos de ejecución. Pero esto último es excepcional, debiendo producirse únicamente cuando sea imprescindible para el ejercicio de las competencias estatales».
} 
garantizar «una definición clara y precisa de los marcos básicos delimitadores de las competencias autonómicas que, siendo fácilmente recognoscibles, evite la incertidumbre jurídica que supone para las CCAA asumir, sin dato orientativo alguno la responsabilidad de investigar e indagar en la masa ingente de las disposiciones normativas reglamentarias estatales, una definición que es al Estado a quien corresponde realizar por encargo directo de la Constitución. En este sentido, la función del Tribunal Constitucional es evitar la ambigüedad permanente, aunque el sistema tendrá siempre un carácter abierto hasta que se defina lo básico, y procurar que su definición no quede a la libre disposición del Estado». Por estas dos razones —continúa la sentencia- hay que establecer un concepto material de bases y señalar que lo básico debe figurar en una ley formal, pues ya se ha superado la primera etapa de adaptación de la legislación preconstitucional, siendo necesario exigir ahora con mayor rigor formal la necesidad de que lo básico venga determinado por una ley votada en Cortes.» La misma doctrina se ratifica y actualiza en las más recientes SSTC 37/2002, 139/2005 y 148/2006, para reconocer que tienen como finalidad el establecimiento de un mínimo uniforme en todo el territorio estatal en aras del interés general. La definición de este interés general le corresponde exclusivamente a las Cortes generales, que tienen un amplio margen de apreciación e iniciativa política en su establecimiento, modificación y actualización ${ }^{28}$.

\section{LA CUESTIÓN DE LA «LEX REPETITA» EN LA LEGISLACIÓN DE LAS CCAA}

La jurisprudencia más reciente del TC en materia de legislación básica aborda el problema que supone la mera reiteración de las normas básicas o delimitadoras del Estado por la legislación de las CCAA; en un primer momento $^{29}$, para advertir que, de acuerdo con la doctrina establecida en la STC $76 / 83$ sobre la reproducción de preceptos constitucionales en la legislación ordinaria del Estado y en los similares supuestos de Leyes autonómicas que reproducían normas incluidas en la legislación básica del Estado (SSTC 40/ 1981 y 26/1982), también, cuando por Ley ordinaria se reiteran preceptos contenidos en una Ley Orgánica; se trata de prácticas legislativas que promueven la confusión competencial y pueden conducir a la inconstitucionalidad sobrevenida de la norma autonómica, cuando el precepto reproducido pierde su vigencia o es modificado, manteniéndose vigente, sin embargo, el que lo reproducía. Para el TC este riesgo es de especial intensidad cuando concurre el vicio de incompetencia material de la Comunidad Autónoma: «porque si la reproducción de normas estatales por Leyes autonómicas es ya una técnica peligrosamente abierta a potenciales inconstitucionalidades, esta

\footnotetext{
28 García Morillo (1996), «La versatilidad de lo Básico». RAP, núm. 139, CEPC, Madrid

${ }^{29}$ FJ 3 de la STC 162/96 y STC 150/1998, de 2 de julio.
} 
operación se convierte en ilegítima cuando las Comunidades Autónomas carecen de toda competencia para legislar sobre una materia» ( SSTC 10/82, 62/91 y 147/93), en las que la simple reproducción por la legislación autonómica además de ser una peligrosa técnica legislativa, incurre en inconstitucionalidad por invasión de competencias en materias cuya regulación no corresponde a las Comunidades Autónomas. Se trata de afirmaciones que carecen de la necesaria contundencia, puesto que la reiteración de preceptos completos de las leyes del Estado por leyes autonómicas, en materias en las que carecen de competencias, tienen que declararse inconstitucionales y absolutamente nulas. La repetición o reiteración sólo puede aceptarse y entenderse en supuestos excepcionales como el resuelto por la STC 47/2004, en que la reiteración simplemente consiste en incorporar a la normativa autonómica, ejercida ésta en su ámbito competencial, determinados preceptos del ordenamiento procesal general con la sola finalidad de dotar de sentido o inteligibilidad al texto normativo aprobado por el Parlamento autonómico. Esta doctrina constitucional se perfilará definitivamente en la STC 341/2005, que distingue la reproducción de normas estatales por las autonómicas en función de que se obre en materias sobre las que la CCAA tengan competencias normativas (de desarrollo, normalmente) o carezcan de tales competencias. Para esta jurisprudencia; la inconstitucionalidad sólo procede cuando la CA carece de toda competencia legislativa; si la tiene, al margen de reproches de técnica legislativa, la consecuencia - afirma el Tribunal- no será siempre la inconstitucionalidad, sino que habrá que estar a los efectos que tal reproducción pueda producir en el caso concreto ${ }^{30}$.

El problema se complica todavía más, cuando no sólo se permite repetir, sino complementar materias propias de ley orgánica ${ }^{31}$, como autoriza la STC 135/2006, complementos que resultan de muy difícil calificación, al autorizar la presencia de la legislación de la Comunidad Autónoma en una materia de competencia exclusiva del Estado, que introduce el concepto de legis-

\footnotetext{
${ }^{30}$ Puede verse una modificación de la doctrina constitucional que ya no fundamenta la relación normas de bases leyes de desarrollo en el concepto de competencia; puesto que de hacerlo, la consecuencia no podría ser otra que la inconstitucionalidad de la norma autonómica.

${ }^{31}$ STC 173/98 F $6^{\circ}$ En primer lugar, debe tenerse en cuenta que la Comunidad Autónoma, al regular el régimen jurídico de las asociaciones sometidas a su competencia, no puede entrar a regular el desarrollo directo de los elementos esenciales del derecho fundamental de asociación. Este es un ámbito reservado al Estado $e x$ art. 81.1 CE y las normas que las Cortes Generales pueden dictar en su ejercicio constituyen un prius del que necesariamente debe partir la Comunidad Autónoma al regular, no el derecho de asociación en cuanto tal, sino el régimen de las asociaciones que surgen del ejercicio de ese derecho. lo más relevante para la resolución del recurso de inconstitucionalidad no radica tanto en la distinción entre la naturaleza jurídica de la reserva de ley y las reglas de competencia, cuanto en la delimitación del alcance material de la reserva de Ley Orgánica y en la determinación de en qué medida esta delimitación debe hacerse o no a partir del sistema de distribución de competencias. Precisando un poco más esta definición, en la STC 132/1989, referida precisamente al derecho de asociación, se afirma que lo que está constitucionalmente reservado a la Ley Orgánica es «la regulación de determinados aspectos esenciales para la definición del derecho, la previsión de su ámbito y la fijación de sus límites en relación con otras libertades constitucionalmente protegidas». Esta doble referencia a «aspectos esenciales» $y$ al «establecimiento de restricciones o límites» se halla también en las SSTC 88/1995, 140/1986 y 101/1991.
} 
lación complementaria de ley orgánica, sin que sepamos qué contenido y alcance puede tener. En resumen, no puede aceptarse - tanto por infracción del reparto constitucional de competencias, si se mantiene una teoría competencial a la hora de afrontar los conflictos leyes de bases desarrollo por las CCAA, como si se aplica la teoría funcional de las normas básicas ${ }^{32}$ - una asunción total y completa de la legislación básica por las leyes de desarrollo más allá de lo necesario para su mejor encuadramiento, definición y formulación.

\section{LA CLÁUSULA DE PREVALENCIA DEL DERECHO DEL ESTADO: SU ALCANCE Y SIGNIFICADO}

El origen inmediato del principio de prevalencia del derecho estatal de nuestra Constitución está en el artículo 21 de la Constitución de 1931 «el Derecho del Estado español prevalece sobre el de las Regiones autónomas en todo lo que no esté atribuido a la exclusiva competencia de éstas en su respectivo Estatuto,» sin obviar el referente directo del artículo 31 de la Constitución Federal Alemana: «El derecho federal deroga el derecho de los lander», el antecedente original de la «cláusula de supremacía» del derecho estatal - de estilo en todos los ordenamientos compuestos- hay buscarlo en el artículo VI, apartado 2, de la Constitución de los EEUU, de 1787: «Esta Constitución y las Leyes de los Estados Unidos que sean hechas en conformidad con la misma... serán el supremo Derecho de la tierra, y los jueces de todo los Estados quedarán vinculados a él aun cuando las Constituciones y las Leyes de los Estados establezcan cualquier cosa contraria al mis$m o »^{33}$. La supremacía se predica de las leyes (made in pursuance thereof), hechas de acuerdo con la Constitución. La prevalencia del Derecho estatal indica que, en la inevitable concurrencia normativa entre los dos centros de poder, la participación de la norma estatal es preferente y expresa la voluntad del interés general del Estado en ese aspecto o materia concreta (ENTERRÍA); la cláusula de prevalencia puede jugar un papel similar en los supuestos de superposición de títulos competenciales —estatales y comunitarios- sobre el mismo objeto o materia. La superposición o concurrencia de títulos competenciales sobre el mismo objeto es consecuencia de la complejidad de los

\footnotetext{
32 Gómez-Ferrer, al rechazar en este caso la aplicabilidad de la noción de competencia, y al no ser, por razones obvias, aplicables los criterios de jerarquía y de posterioridad, elabora la noción de función constitucional. La noción de función constitucional permitiría reconducir el problema a los términos de validez-invalidez, al igual que cuando nos encontramos ante una relación de competencia o de jerarquía. En suma, esa noción, que parte de la consideración de que las normas básicas permiten salvaguardar unos mínimos uniformes en todo el territorio nacional en aras de un interés general que define la propia norma básica, comportaría que, en caso de choque entre la norma básica estatal y una norma autonómica, sea ésta anterior o posterior, el conflicto pueda resolverse en términos de validez-invalidez de una u otra norma.

33 Desde la gran obra judicial de MARshall hasta hoy, esta cláusula se ha considerado como la clave de bóveda de todo el sistema federal americano (SCHWARTZ).
} 
criterios de distribución de competencias. Su heterogeneidad no favorece que los repartos de las respectivas constituciones y, en especial la CE de 1978, delimiten por completo y por separado el campo de materias y el de las propias competencias. Normalmente, terminan por entrecruzarse entre sí, y ésta es justamente la fuente de los conflictos de competencia, la necesidad de articular en un sistema esa heterogeneidad de funciones ${ }^{34}$.

\subsection{Controversia conceptual}

El artículo 149.3 CE tiene un triple contenido: la llamada cláusula residual o de cierre del sistema, que atribuye al Estado todo lo no asumido por las CCAA en sus respectivos Estatutos. Lo que ha tenido y tiene importantes consecuencias prácticas y explica por sí sola la cada vez mayor extensión de los Estatutos de Autonomía. La cláusula de suplencia, que sigue ofreciendo más problemas que soluciones a la hora de encontrar un papel a la aplicación supletoria del Derecho del Estado en el ordenamiento de las CCAA. Y la cláusula de prevalencia del derecho estatal, que no ha tenido operatividad en la jurisprudencia constitucional. La prevalencia del Derecho estatal se ha defendido doctrinalmente desde las posturas más variadas ${ }^{35}$; desde posiciones de exclusividad ${ }^{36}$, hasta como cláusula delimitadora de competencias. Para De Otto y Pardo ${ }^{37}$, implica que el Estado posee competencia normativa general, a la que se superpone la de las Comunidades Autónomas —el Derecho estatal nunca será nulo por incompetencia, sino sólo quedará desplazado por el Derecho autonómico en aquellas Comunidades Autónomas que hayan ejercitado su competencia normativa en la materia-. Lo que significa atribuir una función supletoria generalizada al derecho del Estado que no se corresponde con una jurisprudencia constitucional consolidada sobre el alcance de

\footnotetext{
${ }^{34} \mathrm{El}$ conflicto entre títulos constitucionales es ya usual en materia de urbanismo, título que define una competencia autonómica exclusiva de las Comunidades en el número 3 del artículo 148: «ordenación del territorio, urbanismo y vivienda», cuando entra en conflicto con los títulos competenciales generales del Estado; entre otras, la Sentencia de 13 de mayo de 1986. Sin embargo, el juego de esta cláusula no está plenamente acepado por el TC que prefiere agotar la exploración de las competencias exclusivas de las CCAA antes de acudir a la cláusula de prevalencia, como demuestra la célebre S. 61/97, de 20 de marzo, que declara inconstitucional una parte más que sustancial del TR 1/92, de la Ley del Suelo del Estado por invasión de competencias exclusivas de las CCAA, sin utilizar la cláusula de prevalencia del derecho del Estado sino también la de competencia.
}

35 Sobre esta cláusula, vid., entre otros, F. BALAgUer CALlEjón, «La cláusula de prevalencia del artículo 149.3 CE y los Estatutos de autonomía», en Revista Valenciana d'Estudis Autonòmics, núm. 4, 1986, págs. 132-33; J. CANTERo RODRÍGUEZ, «Nuevas reflexiones sobre la cláusula de prevalencia», en REALA, núm. 269, 1996, pág. 128.

\footnotetext{
36 TEJEDOR BIElSA, La garantía constitucional de la unidad del Ordenamiento en el Estado autonómico, Civitas, Madrid, 2000, págs. 92 ss., entiende que, a efectos de la aplicabilidad de la cláusula de prevalencia, lo relevante es que exista una reserva íntegra y excluyente de toda posibilidad de acción sobre una materia desde cualquier perspectiva y finalidad; de lo contrario, no se cumpliría la finalidad de la atribución de competencias al Estado.

37 «La prevalencia del Derecho del Estado», en Estudios de Derecho estatal y autonómico, Civitas, Madrid, 1986, págs. 66 ss.,
} 
la supletoriedad del derecho del Estado, en materia de competencias exclusivas de las CCAA (SSTC 61/97, y 118/96) ${ }^{38}$.

En el mismo sentido, las tesis de PAREJo AlFonso: «La prevalencia del Derecho del Estado», CEC, Madrid, 1981, parten tanto de la superioridad de las bases sobre las normas de desarrollo como de la consideración de la regla de prevalencia como norma de competencia y no de conflicto en los ámbitos reseñados en el artículo 149.1 CE, y más que delimitarlos terminaría por modificar el sistema constitucional de atribución de competencias, vaciando de contenido y de significado la exclusividad de las competencias asignadas o asumidas por las CCAA. En el mismo sentido, TORNOS MÁs ${ }^{39}$, para quien la conversión de la regla de prevalencia en norma de competencia supone alterar lo previsto en la CE y los Estatutos; a lo que añade que la exclusividad competencial es compatible con la división entre bases y desarrollo, de modo que la prevalencia del Derecho del Estado no debería aplicarse sin más en los supuestos del artículo 149. Añade así que atribuir primacía al Derecho estatal como norma de competencia supone conferir a este Derecho estatal una función delimitativa de la competencia autonómica que imposibilita la existencia de competencias exclusivas de las CCAA.

Para E. García de Enterría y T. R. Fernández Rodríguez, Curso de Derecho Administrativo, I, 7. . Ed., Civitas, Madrid, 1995, págs. 332 ss., la cláusula de prevalencia no constituye una norma de competencia, responde a la necesidad funcional de priorizar el derecho estatal en los casos de concurrencia de títulos normativos contrapuestos e igualmente válidos. Implica que las dos instancias de poder legislativo -Estado y CCAA - actúan en el ejercicio de competencias o títulos legítimos. No es pues una norma de competencia sino de conflicto entre regulaciones válidas y concurrentes, por la que el Derecho del Estado desplaza al autonómico. Los conflictos pueden plantearse y de hecho se plantearán en los supuestos de colaboración y en los de superposición de títulos ${ }^{40}$; también de competencia ${ }^{41}$, porque tienen como presupuesto la existencia de dos normas concurrentes y válidas, de modo que se hace primar una sobre la otra; pero, si ambas son válidas, quiere decir que ambas

\footnotetext{
${ }^{38}$ DE OTTO, Derecho Constitucional. Sistema de fuentes, Ariel, Barcelona, 1987, pág. 282, algún tiempo más tarde, modificó su postura y acabó entendiendo que la cláusula de prevalencia sólo podría operar en caso de concurrencia de competencias por defectos en el sistema de reparto de las mismas.

39 J. ToRnos MAS (1983), «La cláusula de prevalencia y el artículo 4 de la LOAPA», en REDA, núm. 37, págs. 185 ss., quien la considera una norma de conflicto. En el mismo sentido, J. GARCíA ToRRES, «La cláusula de prevalencia y el Poder judicial», en Homenaje a García de Enterría, I, Civitas, Madrid, 1991, pág. 571.

${ }^{40}$ E. GARCÍA DE ENTERRÍA (1985), «Ordenamiento estatal y ordenamientos autonómicos: sistema de relaciones», en Estudios sobre autonomías territoriales, Civitas, Madrid, pág. 356, para quien su aplicabilidad presupone la competencia de ambas instancias.

${ }^{41}$ I. LASAgabaster ERRARTE (1991), Los principios de supletoriedad y prevalencia del Derecho estatal respecto al Derecho autonómico, Civitas, Madrid, pág. 162.
} 
PROBLEMAS DE APLICACIÓN DE LA CLÁUSULA DE PREVALENCIA DEL DERECHO DEL ESTADO

son competentes, luego no estamos ante una norma de competencia, sino de conflicto $^{42}$.

Para el TC, tampoco puede hablarse de una preferencia o preponderancia genérica de los intereses estatales sobre los comunitarios - STC 56/86, de 13 de mayo-; en realidad, para la doctrina constitucional mayoritaria, es la competencia la que determina el interés y no a la inversa; por esta razón, en la resolución de los conflictos de competencias normativos y, en especial, en materia de legislación de bases versus legislación de desarrollo mantiene, desde sus primeras sentencias, que debe apurarse al máximo la interpretación del ámbito de los respectivos títulos competenciales, siguiendo la línea marcada por la STC 77/84. Sin que desde luego se conceda un mayor valor intrínseco a las bases sobre el desarrollo legislativo de las CCAA, evitando, una vez más $\mathrm{y}$ en mayor medida, teorizar en abstracto sobre el funcionamiento ideal de las reglas de reparto de competencias en la $\mathrm{CE}$, y relegando cualquier doctrina sobre el objeto y alcance de la cláusula de prevalencia que, para la doctrina mayoritaria, no atribuye competencia alguna. En el fondo el efecto desplazamiento de la cláusula de prevalencia viene definido tanto por la libertad reconocida al legislador estatal para definir los fines de interés general, como por el necesario respeto a las competencias y a los intereses autonómicos, que no pueden ser anulados por un cambio en la visión del legislador estatal, sino tan sólo, desplazados por las nuevas bases. Así, la regla de la prevalencia no es una norma de competencia, sino un efecto de las normas de bases o de la legislación sobre condiciones básicas.

\subsection{Alcance del principio de prevalencia en CE de 1.978}

Los conflictos normativos propios de los Estados Compuestos pueden tener distintas soluciones, desde la aplicación de la jerarquía hasta la regla de la competencia, sin perjuicio de utilizar los de especialidad, o el de preferencia. En la doctrina del TC, el principio de prevalencia se utiliza en la resolución de conflictos entre el derecho del Estado y el de las CCAA para los supuestos de inoperancia de la regla de la competencia; al concurrir, en principio, dos legislaciones aparentemente válidas sobre la misma materia con un título constitucional legítimo ${ }^{43}$. De hecho, la prevalencia puede ser consecuencia tanto de la superposición de dos títulos competenciales, como de supuestos

\footnotetext{
${ }^{42}$ Sobre los criterios de resolución de conflictos en caso de actuaciones públicas ejecutivas, M. PEÑARRUBIA IZA, «Preferencia, coordinación y prevalencia en el ejercicio de competencias concurrentes», en el núm. 149 de la $R A P, 1999$, págs. 131 ss.

43 JESÚs LEGINA VILLA (1993), «Notas sobre los principios de concurrencia y prevalencia en la legislación compartida». REALA, núm. 258, abril junio, pág. 233, siguiendo a Fernández Farreres entiende «...la prevalencia del derecho estatal no altera el orden constitucional de competencias ni juega en contra del principio de competencia, lo que impide que sea aplicable a los supuestos de colisión normativa en materia de competencias compartidas o de entrecruzamiento de títulos competenciales ratione materiae. Conflictos que deben resolverse atendiendo al criterio de competencia».
} 
de especialidad de las leyes, con el que tiene cierta similitud el concepto de legislación básica del artículo 149.1, que cuenta con el reconocimiento de un amplio margen de discrecionalidad política en favor del Estado para su determinación ${ }^{44}$. Una parte de la doctrina niega así cualquier efecto a la cláusula de prelavencia en materia de conflictos normativos leyes de bases-normas de desarrollo en la CE; sin embargo, este principio, desde su formulación por el juez Marshall para las leyes conformes con la constitución, excluye la jerarquía (Enterría), pero reclama una especial función a las leyes constitucionales, que no puede ser otra que su aplicación preferente o prioritaria.

Efectivamente, las respuestas doctrinales dadas sobre el supuesto mayor valor del derecho del Estado están condicionadas por el alcance que se otorgue a la regla de prevalencia. En general, si se admite la aplicación de dicha regla constitucional en el ámbito de la legislación compartida, la respuesta será afirmativa; por el contrario, si se rechaza tal aplicación y se entiende que ésta sólo es posible en el limitado campo de la concurrencia legislativa -el Estado y la Autonomía actúan con título propio y de igual valor, con carácter exclusivo (LASAGABASTER)-, la respuesta será forzosamente negativa ${ }^{45}$. Sin embargo, no puede aceptarse que la contradicción entre una ley estatal y una autonómica, válidamente dictadas en la regulación de una materia de competencia legislativa concurrente (bases-desarrollo), excluya el recurso a la prevalencia para aplicar la ley estatal válida e inaplicar la también válida ley autonómica. Es evidente que la cuestión reviste especial interés - desde la acepción de la doctrina del TC, bases (normativa general uniforme del Estado) normas de desarrollo particular (políticas propias de las CCAA)— por afectar a la mayoría de la producción legislativa de las CCAA, y tiene una extraordinaria importancia constitucional, pues se trata nada menos que de mantener intacto, como hasta ahora, el monopolio del control de constitucionalidad de todas las leyes en el Tribunal Constitucional o, por el contrario, introducir un sistema alternativo de control judicial difuso sobre la aplicación de las leyes autonómicas complementarias de la legislación básica del Esta$\mathrm{do}^{46}$, sólo para el supuesto exclusivo de cambio de la legislación básica contrario a la ley autonómica o para el establecimiento de nuevas condiciones básicas.

\subsection{La Cuestión del «mayor valor» del derecho Estatal}

Toda organización compleja se sostiene sobre la máxima de la superioridad del sistema general sobre los subsistemas que lo integran; no es una cues-

\footnotetext{
${ }^{44}$ MARía José Alonso MAS (2003), «La prevalencia del derecho del Estado y la inaplicación judicial de las leyes autonómicas: el caso de las cesiones de aprovechamiento en suelo urbano». $R A P$, núm. 16,1 mayo-agosto, 2003. CEPC Madrid.

${ }^{45}$ Para esta doctrina, las relaciones entre bases normativas del Estado y su desarrollo por las CCAA se rigen exclusivamente por la naturaleza exclusiva de las respectivas competencias.

46 Jesús Leguina VilLA, Opus cit num 34.
} 
tión dogmática o ideológica, es una necesidad funcional y hasta una condición de viabilidad. Su aplicación a la teoría del Estado se la debemos al citado Juez MARSHALl que estableció las bases de la doctrina de la supremacía del derecho federal en el artículo VII de la constitución Americana: «los Estados (miembros) no tienen poder para retardar, impedir, gravar, o en cualquier manera intervenir las operaciones legislativas que dentro de la Constitución hace el Congreso para llevar a término los poderes de que está investido para el gobierno general». Esta es, pensamos, la inevitable consecuencia de la supremacía que la Constitución ha declarado ${ }^{47}$. La cláusula de supremacía se configura en el sistema constitucional americano como una prevención contra el principio de igualdad entre los dos centros de gobierno, haciendo que sea dominante el de la Federación. Las mismas consideraciones son aplicables a nuestro sistema constitucional que atribuye al Estado las competencias mínimas para que pueda cumplir su función; con independencia de las distintas posiciones doctrinales y de las distintas posiciones políticas, la distribución de competencias que establece la CE debe interpretarse en el sentido de corresponder al Estado las competencias exclusivas, necesarias e inseparables de su personalidad, que resultan imprescindibles para mantener la unidad global del sistema y su cohesión última, sin renunciar a la mayor eficacia administrativa y financiera. Si bien ese mayor valor no convierte al Estado en superior jerárquico respecto de las normas autonómicas; lo que, a su vez, impedirá hablar de devaluación del rango de las leyes autonómicas.

\subsection{La cláusula de prevalencia y las relaciones entre las normas básicas y la legislación de desarrollo de las CCAA}

La doctrina del TC sobre el alcance de las normas armonizadoras y las propias normas básicas establecida en las 76/83 (LOAPA) y 214/89 (LBRL) prohibe que las normas estatales determinen en abstracto el alcance de las respectivas competencias, en la medida en que ello supondría la atribución del Poder Constituyente, doctrina que se ratifica en la S. 15/2000, de 20 de enero, para referirla a los supuestos en que el legislador estatal pretenda imponer al legislador autonómico una única interpretación vinculante para dicho legislador. Lo propio de la legislación básica, aunque el TC no asuma la teoría funcional de las normas básicas, en la medida en que tienen como finalidad el establecer una regulación uniforme en todo el territorio nacional en aras del interés general, es cristalizar el interés general en una norma de común aplicación a todo el Estado ${ }^{48}$. Su contenido y alcance variará según el propio concepto de interés general que las Cortes sustenten en cada caso.

\footnotetext{
${ }^{47}$ Sentencia TS EEUU, Mc Culloch, 1819.

${ }^{48}$ J. ToRnos Más (1991), «La legislación básica en la jurisprudencia del TC». RVAP, núm. 31/91, entiende que las leyes básicas pertenecen al bloque e constitucionalidad en la medida en que configuran el ámbito de la potestad autonómica.
} 
Si bien el interés general no es una cláusula atributiva de competencia, sí actúa como tal por remisión expresa de la CE SSTC 40 y 65 de $1998^{49}$.

En definitiva, no existe un concepto abstracto y cerrado que nos permita describir lo básico de una materia, como si se tratara de una categoría filosófica; por el contrario, la legislación básica está caracterizada por su variabilidad y por una cierta indeterminación que, indudablemente, dificultan gravemente fijar con precisión los límites de la competencia estatal para dictar normas básicas y, consiguientemente, de la competencia autonómica para desarrollarlas ${ }^{50}$. La doctrina constitucional no es pródiga en declaraciones de inconstitucionalidad de normas del Estado por invasión de competencias autonómicas ${ }^{51}$; En realidad, sólo limitan la normativa básica a no impedir el desarrollo legislativo autonómico, correspondiéndole al propio legislador estatal determinar el alcance de la regulación básica y al cumplimiento de autodeclaración expresa por norma con rango de ley ${ }^{52}$; en este sentido, J. M. ${ }^{a}$ BAÑO DE LEÓN ${ }^{53}$ atribuye un papel decisivo al legislador estatal en la definición del concepto y alcance de lo básico. Por estas dificultades, las relaciones entre las normas de bases y su desarrollo normativo se han excluido del principio de competencia, en la medida en que una relación de competencia presupone (GÓMEZ-FERRER) una delimitación clara y precisa de los distintos ámbitos de actuación que se ha demostrado imposible y que, además, como señala PAREJO ALFONSO ${ }^{54}$, no explica la primacía de ley estatal sobre la regional. En definitiva, hay que convenir que es el interés general implícito en los títulos competenciales del artículo 149.1. CE el que concede tal primacía ${ }^{55}$.

Por todas estas consideraciones doctrinales, parece concluyente que las relaciones entre la legislación básica y la legislación de desarrollo no pueden regirse sólo exclusivamente por la regla de competencia ${ }^{56}$. La legislación

\footnotetext{
${ }^{49}$ S. MuÑoz Machado (1992), «Derecho Público de las CCAA», I Civitas, Madrid: Lo básico es un concepto impreciso. Las Cortes tienen un margen de apreciación insustituible, porque se trata de un concepto oscilante, que depende de la idea que en cada momento histórico se tenga sobre el interés general.

${ }^{50}$ G. FERNÁNDEZ FARRERES, «Proceso contencioso administrativo, y procesos constitucionales: alternatividad, simultaneidad y transferencias». En Homenaje a González. Pérez, Civitas, Madrid, 1993.

${ }^{51}$ Pocas SSTC anulan leyes de bases y lo hace con muy limitado alcance (STC 214/89).

${ }^{52}$ DE OTTO Y PARDo, El problema de la anulación constitucional de las normas básicas es poco significativo.

53 «La Ordenación de las normas reguladoras del Régimen Local». En Tratado de Derecho Municipal, I, dirigido por S. MuÑoz Machado, Civitas, Madrid, 1988.

${ }^{54}$ L. PARejo Alfonso (1981), La prevalencia del Derecho Estatal sobre el Regional. CEC, Madrid.

55 Si las relaciones entre la ley básica y las normas de desarrollo fueran estrictamente de competencia, habría que estimar inconstitucionales todos aquellos preceptos autonómicos que se limitan a reproducir la normativa básica. Pero el TC, desde la S. 137/86 aplica una doctrina vacilante y limitada a analizar, si las normas autonómicas se ajustan a las bases estatales.

56 Gómez FERRER MORANT, «Relaciones entre leyes: jerarquía, competencia y función constitucional». RAP, núm. 113, 1.987
} 
básica tiene la función constitucional de definir un interés general y establecer una legislación de uniforme aplicación. La extralimitación de la competencia estatal sería, a fin de cuentas, inconstitucional por extralimitación funcional. Lo que, mas que una invasión competencial de la competencia legislativa autonómica, impide formular su propia política. Para evitar este riesgo, no procede un reconocimiento general de una supuesta superioridad de la legislación básica estatal que, entre otros efectos, permitiría una aplicación en España de las técnicas del control difuso y hasta el rechazo administrativo de la aplicación de la Ley autonómica ${ }^{57}$, pero no puede negarse que, por su mera formulación, enmarcan y dirigen el desarrollo normativo autonómico, que no podrá ser contradictorio con las bases.

Evidentemente, con la misma fuerza, se ha defendido la posición contraria, que no ve suficiente fundamento constitucional (LEGUINA VILLA) ${ }^{58}$ para conceder más valor constitucional a la ley básica estatal que a la ley autonómica complementaria. La superioridad de los intereses generales, cuya salvaguarda es función de la ley básica estatal, no se corresponde ni atribuye a la norma básica un mayor valor o una mayor fuerza normativa - vincula más fuertemente al juez- de la ley estatal. Ambas leyes tienen el mismo rango y la misma fuerza de obligar. Para este autor, sólo se diferencian por el objeto o la materia que una y otra pueden regular conforme a las reglas de distribución de competencias legislativas que se contienen en el bloque de la constitucionalidad (Constitución y Estatutos, principalmente); Por ello, en ningún caso, a tenor de los artículos 161 y del $163 \mathrm{CE}$, están autorizados los tribunales ordinarios a dirimir conflictos de leyes, viviendo obligados a plantear la cuestión de inconstitucionalidad cuando consideren que «una norma con rango de Ley» de cuya validez depende el fallo pueda ser contraria a la Constitución. Si las leyes básicas tienen alguna función, desde luego no justifican el desplazamiento o inaplicación de la legislación comunitaria por parte de los tribunales ordinarios, por entrañar tal decisión un juicio de constitucionalidad que está reservado al TC.

\section{LA OPERATIVIDAD DE LA CLÁUSULA DE PREVALENCIA EN LA JURISPRUDENCIA CONSTITUCIONAL: LOS VOTOS PARTICULARES A LA STC 1/03 y 178/2004}

El TC no ha modificado la doctrina sobre el alcance de sus funciones, entre las que no figura: «crear apriorísticamente una teoría que prevea todos los supuestos futuros ni anticipar criterios abstractos no contrastados con la realidad tópica» (SSTC 102/1995, de 26 de junio, F. 9, y 156/1995, de 26

\footnotetext{
${ }^{57}$ María José Alonso Más, Op. cit. num 44».

${ }^{58}$ J. Leguina Villa (1993), «Notas sobre los principios de competencia y de prevalencia en la legislación compartida». REALA, Abril-Junio 93, págs. 231 MAP Madrid.
} 
de octubre F. 3), entre otras. De acuerdo con ésta, los conflictos normativos por contradicción entre legislación de bases y de desarrollo pueden y deben ser resueltos directamente, delimitando el campo de las respectivas competencias del Estado y de las Comunidad Autónomas, desde luego sin acudir a un supuesto mayor valor del Estado ni a una preeminencia de las normas básicas. Por lo que se refiere a la operatividadad de la cláusula de prevalencia, la STC 163/95, de 8 de noviembre, sienta una doctrina contraria a su aplicación por los tribunales ordinarios: «la puesta a disposición de los tribunales ordinarios de la cláusula, como si de un sistema de control difuso se tratare, es absolutamente incompatible con los sistemas de jurisdicción constitucional concentrada, como el nuestro, que se basan en el monopolio por parte del Tribunal Constitucional del control de constitucionalidad de las Leyes, según establece el artículo 163 CE, que impone a los órganos judiciales la obligación de plantear la cuestión de inconstitucionalidad cuando duden, en cualquier tipo de proceso, de la adecuación a la Constitución de la Ley de cuya validez dependa el fallo, y así ha venido a corroborarlo la propia jurisprudencia del Tribunal Constitucional desde la temprana STC 4/1981».

En definitiva, la doctrina constitucional vigente no concede a la cláusula de prevalencia el valor defendido por un sector doctrinal minoritario de autorización a los órganos judiciales para acordar la inaplicación de la Ley autonómica que contradiga lo establecido por las bases estatales; sin entrar en la naturaleza ni en el análisis de la cláusula de prevalencia, el TC descarta que pueda utilizarse para realizar el enjuiciamiento de la constitucionalidad de las Leyes por los tribunales ordinarios. Sin embargo, en esta S 163/95, por primera vez, admitirá su valor como cláusula de vigencia, pero no aquellos interrogantes que impliquen un juicio de constitucionalidad $\mathrm{y}$, por consiguiente, de validez de la norma; es decir, no admite un efecto derogatorio de la legislación del Estado, por lo tanto — sigue el TC — ...la reiterada cláusula pretende garantizar la prevalencia del derecho estatal cuando proceda, pero siempre y cuando no implique un enjuiciamiento de la Ley autonómica, pues, de lo contrario, si se permitiese a los Jueces y Tribunales efectuar este tipo de control y optar, en su caso, por su inaplicación, ello supondría una gravísima vulneración de los elementos estructurales claves en que se sustenta el Estado Autonómico, al privar a las leyes autonómicas de la nota de irresistibilidad, con lo cual, en muchos aspectos, más tendrían en común con los reglamentos que con verdaderas leyes»; con estas consideraciones, puede decirse que no aclara nuestro TC cuándo procede la aplicación de la cláusula, pero desde luego excluye que, a su amparo, los tribunales enjuicien la constitucionalidad de las leyes. Prohibición que no excluye «a radice»su posible aplicación como cláusula de vigencia por los jueces y tribunales, a la hora de seleccionar el derecho aplicable. Lo discutible es si la selección entre leyes autonómicas y nuevas bases o condiciones básicas del Estado, implica un enjuiciamiento constitucional en todo caso o, sencillamente, se trata de un problema de vigencia y no de validez o constitucionalidad. 


\subsection{Cláusula de prevalencia e igualdad en el ejercicio de derechos}

Sólo en una ocasión, por el momento, el TC ha dado carta de naturaleza a la cláusula de prevalencia, la S. 173/98 de 28 de julio, recaída en el recurso promovido por el presidente de la nación contra la ley vasca de asociaciones 3/1988, en la que el TC, curiosamente, teoriza en abstracto sobre el alcance de la competencia del art. $149.1 .1^{a} \mathrm{CE}$, razonando que: «habilita, pues, al Estado para regular el contenido primario, las facultades elementales y los límites esenciales en aquello que sea necesario para asegurar una igualdad de los españoles en el ejercicio del derecho de asociación. Las leyes que se aprueben por el Estado con base y fundamento expreso en este precepto obligan y vinculan al legislador autonómico, aunque disponga de competencia exclusiva, pormenorizadamente asumida en su Estatuto de Autonomía. Tal legislación constituye un prius del que ha de partir toda regulación sobre la materia de que se trate. Ahora bien, esta vinculación no será posible en abstracto. Lo que implica que, sin legislación estatal al efecto, será difícil atribuir a la legislación autonómica una invasión competencial». Para el TC, el art. 149.1.1 ${ }^{\text {a }} \mathrm{CE}$, más que reservar al Estado una determinada competencia o delimitar un ámbito material excluyente de toda intervención de las Comunidades Autónomas, habilita la actuación del Estado para que mediante, precisamente, el establecimiento de unas «condiciones básicas» uniformes, condicione el ejercicio de esas competencias autonómicas, con el objeto de garantizar la igualdad de todos los españoles en el ejercicio de sus derechos y en el cumplimiento de sus deberes constitucionales: «En suma, si el Estado considerara necesario establecer en el futuro esas condiciones básicas y al dictarlas éstas entraran en contradicción con preceptos de leyes autonómicas en vigor, estos últimos quedarían automáticamente desplazados por aquéllas, ya que, como queda dicho, constituyen un núcleo de regulación uniforme del que ineludiblemente debe partir la regulación de los distintos tipos de asociaciones». La doctrina constitucional aplica la cláusula de prevalencia con un efecto de desplazamiento: La Ley de la Comunidad Autónoma no deviene inconstitucional por incompetencia, es desplazada por la vigencia de la Ley Estatal, dictada en materias para las que el Estado está habilitado directamente por la CE, asumiendo así el concepto de norma de conflicto predicado por la doctrina.

\subsection{Cláusula de prevalencia y legislación básica}

La STC 1/03 aborda el espinoso problema de la colisión o contradicción entre la legislación básica del Estado y la legislación de desarrollo por la CCAA;.en primer lugar, el TC recuerda la necesidad de buscar una interpretación que permita su aplicación conjunta (se debe intentar encontrar una interpretación coherente que evite toda contradicción, hasta agotar la regla 
de la competencia); puesto que, al final, se trata de aplicar ambas legislaciones, buscando la interpretación más adecuada a la Constitución y el orden constitucional de distribución de competencias (STC 236/2000, de 16 de octubre, FF. 3 y 5 , y art. 5 de la LOPJ); operativa que obliga al TC a entrar en la delimitación concreta, caso por caso, de lo básico y en el análisis de cada precepto impugnado y de los que, a su juicio guarden conexión ${ }^{59}$. La doctrina mayoritaria del TC huye de la aplicación directa de la cláusula del mayor valor del derecho del Estado, que sólo aparece expresamente reconocido en algún voto particular, como el formulado a esta Sentencia 1/2003, en el que se asume sin ambages la preferente aplicación de la normativa básica estatal, pues la legislación básica debe prevalecer sobre las Leyes autonómicas que, a pesar de haber sido aprobadas válidamente en su momento, no resultan del ejercicio de competencias exclusivas —en sentido estricto- de las Comunidades Autónomas, sino de competencias de «desarrollo legislativo» de las bases del Estado, como era aquí el caso.

La importancia del voto particular de esta STC 1/2003, estriba en el intento expreso de buscar una teoría general de interpretación y aplicación de la cláusula constitucional de prevalencia por los tribunales ordinarios, reconociendo la aplicación de una especie de control de constitucionalidad difuso; al menos, en el particular efecto de legislación básica estatal posterior a la legislación de las CCAA: «todos los Tribunales de Justicia tienen la facultad de resolver directamente las colisiones que se producen —cada vez. con mayor frecuencia - entre las normas autonómicas, aprobadas válidamente en su momento, y las posteriores Leyes del Estado que modifican las bases de una materia. Si el Juez estima que la Ley estatal no es realmente básica, a pesar de declararse como tal, y que por tanto la Ley estatal vulnera el art. 149 CE), debe elevar cuestión de inconstitucionalidad. Sin embargo, si el Juez. estima que la Ley estatal es básica, tanto material como formalmente (SSTC 69/1988, de 19 de abril, F. 6, y 233/99, de 20 de diciembre, F. 5), deberá fallar de conformidad con la Ley estatal, en su caso inaplicando la Ley autonómica que resulta incompatible con ella, exactamente igual que si la Ley de la Comunidad Autónoma contradijera disposiciones del Derecho comunitario ${ }^{60}$. En cuanto a los efectos de esta prevalencia, para este voto particular: «... no da lugar a la nulidad de la norma autonómica, que fue válida en el momento de su aprobación cuando las bases del Estado eran diferentes, sino a su inaplicación, una vez que las nuevas normas básicas del Estado despliegan su eficacia, comprimiendo o desplazando a las de la Comunidad

\footnotetext{
59 STC 1/2003 FJ 8: «Hemos de recordar también nuestra doctrina de que «la intensidad y extensión que pueden tener las bases no es la misma en todos los ámbitos que integran ese régimen jurídico. Así, el alcance de lo básico será menor en aquellas cuestiones que se refieren primordialmente a la organización y al funcionamiento interno de los órganos de las Administraciones públicas que en aquellas otras que inciden más directamente en su actividad externa, sobre todo cuando afectan a la esfera de los derechos e intereses de los administrados».

60 SSTC 28/1991, de 14 de febrero F. 6, y 64/1991, de 22 de marzo F. 4; SSTJCE Simmenthal de 1978, y Ford España de 1989 [TJCE 1990, 12], FF. 17-19.
} 
PROBLEMAS DE APLICACIÓN DE LA CLÁUSULA DE PREVALENCIA DEL DERECHO DEL ESTADO

Autónoma que hasta entonces habían venido rigiendo sin mácula alguna de inconstitucionalidad ${ }^{61}$ ».

\subsection{La doctrina de la STC $178 / 2004$}

El voto particular a esta Sentencia repasa la doctrina constitucional en materia de la cláusula de prevalencia del Derecho estatal sobre el Derecho de las Comunidades Autónomas, para señalar que la Sentencia mayoritaria, sin citarla expresamente y sin reconocerlo abiertamente, se refiere a esta regla de colisión del artículo 149.3 CE, cuando examina la posibilidad de una modificación o del establecimiento ex novo por el Estado de las condiciones básicas a que se refiere el artículo $149.1 .1^{\text {a }} \mathrm{CE}$, puesto que el efecto desplazamiento a que hace referencia: «cuando al dictarlas éstas entraran en contradicción con preceptos de Leyes autonómicas en vigor, estos últimos quedarían automáticamente desplazados por aquéllas» sólo y exclusivamente puede estar fundado en la aplicación de la cláusula de prevalencia, más si se tiene en cuenta que se cita la doctrina de la S 173/1998. Lo que le permite concluir que esta referencia viene a confirmar en parte la validez de su voto particular a la STC 1/2003, de 16 de enero, y que representa un cambio significativo respecto de la propia doctrina mayoritaria del Constitucional, expresada en las STC 163/1995, de 8 de noviembre, y de la misma STC 1/2003, de 16 de enero, F. 9, al abrir la aplicación de la cláusula de prevalencia a los concursos de normas (autonómica y posterior de condiciones básicas) similar al de la legislación concurrente (konkurrierende Gesetzgebung) del artículo 72.1 de la Ley Fundamental de la República Federal alemana $^{62}$, por ser ambas normas en colisión válidas y dictadas en el ejercicio de sus competencias, exclusivas pero en una misma materia, por el Estado y por la Comunidad Autónoma. En definitiva, el TC aplica sin asumirlo ex-

\footnotetext{
${ }^{61}$ Aunque no sea misión del TC elaborar una teoría general sobre los conflictos normativos: «En este momento basta con advertir que todos los Tribunales de Justicia tienen la facultad de resolver directamente las colisiones que se producen — cada vez con mayor frecuencia— entre las normas autonómicas, aprobadas válidamente en su momento, y las posteriores leyes del Estado que modifican las bases de una materia. Si el Juez estima que la ley estatal no es realmente básica, a pesar de declararse como tal, y que por tanto la ley estatal vulnera el artículo $149 \mathrm{CE}$, debe elevar cuestión de inconstitucionalidad (a tenor de los arts. 35 LOTC y 5 LOPJ). Sin embargo, si el Juez estima que la ley estatal es básica, tanto material como formalmente (SSTC 69/1988, de 19 de abril, FJ 6, y 233/ 1999, de 20 de diciembre, FJ 5), deberá fallar de conformidad con la ley estatal, en su caso inaplicando la ley autonómica que resulta incompatible con ella, exactamente igual que si la ley de la Comunidad Autónoma contradijera disposiciones del Derecho comunitario (SSTC 28/1991, de 14 de febrero, FJ 6, y 64/1991, de 22 de marzo, FJ 4; SSTJCE Simmenthal e 1978, y Ford España de 1989, FF.JJ. 17-19)».

${ }^{62}$ Artículo 72 [Legislación concurrente de la Federación, concepto] En el ámbito de la legislación concurrente, los Länder tienen la facultad de legislar mientras y en cuanto la Federación no haya hecho uso mediante ley de su competencia legislativa.

2) En este ámbito, la Federación tiene el derecho de legislar siempre que y en cuanto exista la necesidad de una regulación legislativa federal porque así lo requieran la creación de condiciones de vida equivalentes en el territorio federal o el mantenimiento de la unidad jurídica o económica en interés de la totalidad del Estado. 3) Por ley federal puede determinarse que una regulación legislativa federal que ya no sea necesaria en el sentido del apartado 2, pueda ser reemplazada por la legislación de los Länder.
} 
presamente el efecto desplazamiento de la cláusula de prevalencia, por la entrada en vigor de legislación del Estado, al amparo del 149.1. $1^{\text {a }}$ CE. Sin llegar a un reconocimiento claro, expreso y efectivo, incluso sin citarla más que por referencia, asume el efecto desplazamiento que tal cláusula conlleva, pero rechaza desde luego cualquier intento de establecer o justificar un control difuso o un control compartido de las leyes de las Comunidades Autónomas.

Para una parte de la doctrina ${ }^{63}$, la aceptación de un control difuso no implica necesariamente el desapoderamiento del monopolio del TC en materia de enjuiciamiento constitucional, puesto que podrá recuperar el conocimiento final del asunto, a través de la interposición de un recurso de amparo (S 163/ 95), justificado en el artículo 24 de la CE, tanto por tratarse de una resolución judicial que inaplica una Ley de una Comunidad Autónoma sin justificación y vulnerando así de los derechos a la tutela judicial efectiva, como por causar indefensión o seguir un proceso sin garantías. Ahora bien, sin despreciar la previsible dificultad que puede tener el juzgado o tribunal en establecer la relación de prevalencia, sin una previa labor interpretativa del alcance constitucional de las respectivas leyes, hay que entender que la aplicación generalizada de la cláusula de prevalencia por los órganos judiciales supone una modificación del modelo de justicia constitucional que no puede asumirse, puesto que no puede dudarse que tanto material como formalmente la aplicación de la cláusula de prevalencia envuelve un auténtico y genuino juicio de constitucionalidad, que está reservado en exclusiva al TC.

Por este motivo, la doctrina que late en citado voto particular sobre la STC $178 / 04$, promueve la coexistencia de la jurisdicción constitucional y la ordinaria, en opinión de MARÍA JOSÉ ALONSO MAS, aunque parece dar prioridad a esta última ${ }^{64}$, para dar contenido a un fallo fundado en la aplicación de la prevalencia de las bases estatales, argumenta el voto particular sobre la distinción entre inconstitucionalidad y nulidad de la ley, distinción contradictoria con el propio efecto desplazamiento de esta cláusula, que impide considerar contraria a la Constitución la norma de la Comunidad Autónoma desplazada por la nueva Ley estatal. Por otro lado, la aplicación de la cláusula de prevalencia con su característico efecto desplazamiento, común a toda norma de conflicto, no encuentra acomodo en la regulación vigente (artículos 38 a 40 de la LO 2/79) de los efectos de las Sentencias del Tribunal constitucional en procesos de inconstitucionalidad, de tal manera que la Sentencia que declarase el efecto desplazamiento no tendría cobertura formal, al no suponer la inconstitucionalidad y la subsiguiente nulidad de los preceptos afectados.

\footnotetext{
${ }^{63}$ María José Alonso Más, Op. cit num 44.

${ }^{64}$ «La prevalencia... cit pág. 32»: «Sin embargo, además de que no se puede hablar de contravención con la Constitución en estos casos, y precisamente por ello, la distinción entre inconstitucionalidad y nulidad no parece aquí justificada y resulta artificiosa».
} 


\section{NECESARIA DOCTRINA CONSTITUCIONAL PREVIA}

Si entendemos que la aplicación de la cláusula de prevalencia implica un inevitable enjuiciamiento previo de la competencia del Estado para dictar las normas de bases de los distintos apartados del artículo 149.1 CE o de las condiciones básicas del 149.1.1 ${ }^{\mathrm{a}}$ y un juicio de contraste inevitable con la previa legislación de las CCAA, que resulte contradictoria con esta nueva regulación básica y con estas condiciones básicas que, por otro lado, también pueden ser objeto de un juicio directo de constitucionalidad, resulta que la cláusula de prevalencia no puede ser aplicada directamente por los Tribunales; por el contrario, su aplicación inicial requiere una previa comprobación de la competencia del Estado para dictar normas básicas o establecer condiciones básicas, de la propia adecuación de las mismas a la CE, y contrastar que existe contradicción insalvable con la previa legislación de las CCAA —en materias sobre las que la CA no disponga de competencia exclusiva-; tareas todas propias, en definitiva, de un verdadero y exclusivo juicio de constitucionalidad. No obstante, hay que reconocer que, por los citados problemas del contenido necesario de las Sentencias de inconstitucionalidad del articulo 39 de la LOTC o por otras consideraciones de fondo, por el momento, el TC no ha establecido una doctrina sobre el contenido y la operativa de la cláusula de prevalencia en una Sentencia que vincule futuros pronunciamientos; por el contrario, aún en supuestos de solapamiento de títulos competenciales, se ha inclinado por apurar al máximo las posibilidades de subsumir la norma controvertida en uno u otro título competencial ${ }^{65}$.

Para superar esta dificultad, MARÍA JOSÉ ALONSO propone crear, al amparo del artículo 161.1. d) CE, un nuevo proceso constitucional, que tuviera por finalidad determinar, a solicitud de los órganos jurisdiccionales, cuál es la norma que debe prevalecer entre dos normas válidas, o quizá modificar el mecanismo de la cuestión de inconstitucionalidad, a fin de dar cabida a estos supuestos como pronunciamiento subsidiario. En el fondo, se trataría de abrir un cauce constitucional propio, inspirado en la institución de la «cuestión prejudicial» de Derecho Comunitario, que establece un mecanismo de colaboración entre el TJCE y los órganos judiciales de los Estados miembros, en el artículo 177 del TCEE, por la que los tribunales nacionales están obligados a suspender el proceso y plantear la cuestión al TJCE, cuando la norma de la que dependa el fallo, pudiera vulnerar o contradecir el Derecho Comunitario. Sólo cesa la obligación de plantear la cuestión, si tratándose de una cuestión prejudicial de interpretación, el Tribunal de Justicia ya ha tenido la oportunidad de pronunciarse con carácter previo sobre la interpretación que se suscita o si la correcta aplicación del derecho comunitario se impone con tal evidencia al juez nacional, que no deje lugar a duda razona-

\footnotetext{
${ }^{65}$ Las SSTC 213/88, de 11 de noviembre; 259/88, de 22 de diciembre; 46/92, de 2 de abril y 11/99, de 1 febrero, declaran inconstitucionales normas autonómicas, formalmente amparables en el título competencial del urbanismo, por entender que las mismas eran contrarias a las bases estatales en materia de régimen local, al afectar al sistema de control de legalidad de los actos y acuerdos locales.
} 
ble sobre la manera de resolver la cuestión solicitada (doctrina del acto claro), reiteradamente aplicada por nuestro Tribunal Supremo, con origen en el Consejo de Estado Francés, asunto, L'interieur c/ Cohn Benditt) ${ }^{66}$.

\subsection{La cláusula de prevalencia y los tribunales ordinarios}

Si se entiende que la cláusula de prevalencia no trae consigo una previa delimitación competencial y su aplicación no implica un verdadero juicio de constitucionalidad, como propone una parte de la doctrina —en definitiva, que la relación entre leyes básicas y leyes autonómicas de desarrollo no está sujeta exclusivamente a una precisa delimitación competencial que atribuye en exclusiva el desarrollo normativo a las CCAA-, podrá colegirse que toda modificación de la legislación estatal en materia de bases legislativas y todo establecimiento o modificación de condiciones generales del artículo 149.1.1 ${ }^{\mathrm{a}}$ desplaza a toda previa Ley Autonómica, que tendrá que adecuarse a las nuevas bases o a las nuevas condiciones. De acuerdo con esta interpretación, la cláusula de prevalencia del artículo 149.3 CE tiene un alcance generalizado como norma de conflicto, sin que su aplicación suponga la anulación de la ley autonómica o su declaración de inconstitucionalidad. Lo que permitirá eludir, en definitiva, un proceso constitucional, quedando a disposición de los tribunales ordinarios su aplicación, a los que corresponde a fin de cuentas la selección de la norma aplicable al caso. No obstante, por mucho que se pretenda, no suelen concurrir las pretendidas circunstancias de claridad y sencillez que permitan declarar la prevalencia de la nueva legislación del Estado y el desplazamiento de la previa legislación comunitaria; tal aplicación, a imagen de la doctrina del acto claro en Derecho Comunitario, exige que la conclusión del desplazamiento se desprenda con una evidencia que la experiencia niega o que exista doctrina constitucional al respecto.

Siempre será difícil deslindar la cláusula de prevalencia de la cuestión de la naturaleza exclusiva o compartida de las competencias legislativa de las CCAA, quizá por ello, los pocos pronunciamientos del TC que, hasta la fecha, la aplican preferentemente en aplicación de legislación del Estado dictada al amparo de la cláusula del artículo 149.1.1 ${ }^{\text {a }}$, que autoriza al Estado a establecer un prius o común denominador que, por esencia, no puede corresponder nunca a la competencia autonómica. Cualquier sombra de duda sobre el alcance efectivo de ambas regulaciones o sobre la naturaleza exclusiva de las competencias comunitarias para el desarrollo de la legislación básica, asumidas con ese título en todos los Estatutos y más en el reformado de Cataluña, serían reconducibles a procesos de inconstitucionalidad directos por invasión de competencias exclusivas. En este sentido, hay que considerar que la propia Sentencia del TSJ del País Valenciano de, 20-11-02, que resuelve

\footnotetext{
${ }^{66}$ STJCE. Sentencia de 27 de marzo de 1.963, as. Da Costa -28 a 30/62 Rec. p. 75; Sentencia de 6 de octubre de 1.982 en el as. Cilfit .
} 
PROBLEMAS DE APLICACIÓN DE LA CLÁUSULA DE PREVALENCIA DEL DERECHO DEL ESTADO

a favor de la norma estatal 7/97 sobre la Ley valenciana 14/97 la contradicción aplicando directamente la cláusula de prevalencia, cuenta con previa doctrina del TC que afronta el problema de los límites de las cesiones obligatorias de los distintos tipos de suelo, en la resolución de los recursos de inconstitucionalidad presentados por las CCAA contra la Ley 6/98, de Ordenación del suelo del Estado ${ }^{67}$; luego se limita a la mera aplicación de una doctrina constitucional ya decantada y consolidada.Desde otro punto de vista, hay que reconocer que no puede prohibirse la aplicación de la cláusula de prevalencia por los tribunales ordinarios a los que les corresponde, a fin de cuentas, la selección del derecho aplicable ${ }^{68}$ y la competencia para, bajo su responsabilidad exclusiva, el planteamiento o no de la cuestión de inconstitucionalidad. Sin embargo, será muy difícil que puedan aplicar directamente ésta cláusula. Si no hay un previo pronunciamiento del TC y tienen dudas sobre el derecho aplicable están constitucionalmente obligados a plantear la cuestión de constitucionalidad ante el TC. Sólo en el hipotético supuesto del acto claro, estarían habilitados para aplicar directamente la cláusula de prevalencia. Sin que por ello el TC pierda su monopolio en el enjuiciamiento constitucional, puesto que contra la Sentencia que se dicte podrá interponerse, al menos el recurso de amparo por infracción del artículo $24 \mathrm{CE}$, siempre que se hagan las preceptivas alegaciones y protestas

\section{VALORACIÓN FINAL}

La cláusula de prevalencia del derecho estatal es un mandato constitucional más, que también vincula a todos los poderes públicos; sin embargo, su objeto y alcance sigue siendo controvertido; ni se le reconoce un alcance general ni concede un valor superior a la legislación del Estado sobre la de las CCAA, imponiéndose su consideración como norma de conflicto ${ }^{69}$. De ahí que su verdadero sentido y alcance esté en la resolución de los conflictos normativos, surgidos entre la legislación básica o las condiciones básicas establecidas por el Estado al amparo de los distintos números del artículo 149.1 CE y su correspondiente legislación de desarrollo de las CCAA. Sin que existan motivos para relegar la aplicación de esta cláusula a los supuestos marginales de superposición de distintos y contrapuestos títulos de competencia, excluyendo por completo su aplicación a los conflictos legislativos bases-desarrollo que, tanto por la posición sistemática que ocupa el artículo 149.3, a modo de cláusula de cierre de la regulación constitucional de las reglas

\footnotetext{
${ }^{67}$ «Desde este punto de vista, pues, hay que concluir que, a la luz de la más reciente jurisprudencia del TC, la norma aplicable a este caso era la Ley 7/97, en cuanto que dictada al amparo del legítimo ejercicio de la competencia estatal del artículo 149.1.1 CE; lo que conduce a la desestimación del recurso, al ser correcta en consecuencia la determinación de un porcentaje de cesión del 10\% en suelo urbano en que se actuaba sistemáticamente».

${ }^{68}$ María José Alonso Más, Op. cit num 52.

${ }^{69}$ E. García de ENTERRía, Opus cit num, págs.
} 
del reparto competencial entre el Estado y las CCAA, como por la naturaleza y el alcance que se concede a esta cláusula en los Estados Federales, en especial en la Constitución Federal Alemana de 1949 - y por estar sólo constitucionalmente limitada por no afectar a las de competencias exclusivas de las CCAA-, constituyen su verdadero objeto, que es salvar las contradicciones que las modificaciones normativas de las «bases» pueden generar con la legislación de desarrollo vigente, y posibilitar una aplicación coherente de las dos normativas.

Desde este punto de vista, sólo una interpretación favorable a la consideración de las leyes de desarrollo de las CCAA como competencia exclusiva de las mismas, permitiría la exclusión de la cláusula de su campo de aplicación: la resolución de los conflictos normativos Estado CCAA, generados por una modificación de las bases estatales de una materia o la aprobación de unas condiciones generales y básicas, en la que el elemento temporal o la secuencia temporal adquiere un carácter esencial. Para esta doctrina, la prevalencia sólo opera un efecto desplazamiento de la norma no prevalente en el caso concreto, precisamente porque su validez no queda afectada. Entender lo contrario - añaden - daría lugar a pronunciamientos constitucionales de nulidad que podrían después quedar sin sentido ante un nuevo cambio de la legislación estatal. Lo que no pasa de ser una mera hipótesis, puesto que tal situación requiere la anulación del cambio normativo estatal y la reposición de la ley anterior.

Precisamente, en este exclusivo efecto desplazamiento que no implica una declaración de inconstitucionalidad o nulidad, ni siquiera la mera invalidez de la norma desplazada, se ha querido fundamentar la posibilidad de reconocer una especie de control compartido, más que difuso, de la cláusula de prevalencia; a estos efectos, se razona que el mismo control compartido de constitucionalidad se predica con naturalidad en los decretos legislativos - con los órganos judiciales en casos de extralimitación y la facultad de anulación de los mismos por el orden contencioso-administrativo-, y desde la STC 4/81 se reconoce a los órganos judiciales facultados para elevar cuestión de inconstitucionalidad contra leyes preconstitucionales eventualmente inconstitucionale ${ }^{70}$; no obstante, estos supuestos son marginales y no incluyen la legislación postconstitucional y no tienen el mismo objeto ni alcance. En el fondo, no puede negarse que la aplicación de la cláusula de prevalencia envuelve siempre un juicio de constitucionalidad de leyes, aún cuando se trate de una ley posterior del Estado que desplace a la previa legislación autonómica, sin duda tal desplazamiento requiere que no se trate de una competencia legislativa exclusiva de la CCA, lo que a su vez implica un previo enjuiciamiento de la clase y naturaleza de las competencias de la Comuni-

\footnotetext{
${ }^{70}$ R. BocANEgRA SIERRA, El valor de las sentencias del Tribunal Constitucional, IEAL, Madrid, 1982; del mismo autor, «Sobre el alcance objetivo de las sentencias del Tribunal Constitucional», en Homenaje a García de Enterría, vol. I, Civitas, Madrid, 1991, págs. 515 ss.
} 
PROBLEMAS DE APLICACIÓN DE LA CLÁUSULA DE PREVALENCIA DEL DERECHO DEL ESTADO

dad Autónoma, que figurarán en su Estatuto como exclusivas y con la extensión necesaria para formular políticas propias ${ }^{71}$. De tal suerte que sólo y exclusivamente cuando exista previa doctrina constitucional recaída en supuesto análogo, podría tener aplicación la cláusula de prevalencia por los tribunales ordinarios; en caso contrario, su aplicación muy posiblemente chocará con la declaración de competencia exclusiva estatutaria, que predican los Estatutos de Autonomía de sus competencias legislativas. Calificación que reclama la intervención del TC para establecer su verdadera naturaleza, teniendo en cuenta que una cosa es tener competencia en exclusiva para legislar el desarrollo de las bases, y otra muy distinta que tal competencia sea por naturaleza exclusiva en el sentido de excluir cualquier intervención del Estado, cuando el propio concepto de legislación de desarrollo implica la concurrencia del Estado y de las CCAA para establecer la regulación completa, y cuando el Estado puede intervenir estableciendo condiciones básicas o modificando el alcance de las bases con una nueva interpretación del interés general que pueda tener mayor o menor alcance; en definitiva, confundiéndose a la postre competencia propia con competencia exclusiva ${ }^{72}$.

Quizá el verdadero objeto y sentido de la cláusula de prevalencia esté en la justificación de un poder normativo del Estado inherente al concepto de bases para establecer la dirección y el objeto de toda la normativa. La cláusula de prevalencia es, en definitiva, la garantía constitucional de la supremacía del interés general, y su discusión está reservada en nuestro sistema al proceso de constitucionalidad, con su efecto característico de desplazamiento de la normativa autonómica. La aplicación de la cláusula de prevalencia concurrirá necesariamente con una previa y siempre necesaria declaración de competencia legislativa concurrente y no exclusiva de la CCAA; en este sentido, hay que admitir que la regulación de los efectos de las Sentencias que establece la LO 2/79, no contempla la aplicación de la cláusula de prevalencia con su característico efecto desplazamiento y que, hasta la fecha, cuando el TC ha aplicado la cláusula ha decretado la inconstitucionalidad y la nulidad

\footnotetext{
71 Argullol ha sostenido que la norma básica estatal puede sólo señalar límites, pero no programas o directrices positivas a la potestad normativa autonómica. Es cierto que no podrá señalar directrices vinculantes, en el sentido de excluir la posibilidad de «políticas propias» autonómicas, como ya hemos expuesto, pero deducir de ahí que lo que resta es solamente la formulación de límites resulta excesivo. Lo propio del círculo de encuadramiento es delinear, en efecto, el espacio propio de la normación autonómica, pero también articular esa normación en la «estrategia global» que la legislación básica implica de suyo, y no puede dejar de implicar. No se trata aquí, por tanto, de una simple partición del campo y de que cada uno de los dos partícipes, una vez fijada la línea divisoria, se desentienda por completo de lo que el otro pueda hacer en su espacio propio.

72 E. GARCÍA DE ENTERRÍA (1995), Opus cit num, 5, págs 316 y sts: «La concepción sustancial que subyace a la técnica constitucional de la normación concurrente, la cual, por el contrario, supone que una regulación global se articule con normas de las dos procedencias, pero una regulación global no contradictoria o fragmentada, sino unitaria, coordinada y coherente, como destinada a los mismos sujetos y aplicada (tanto en la esfera administrativa, como inmediatamente veremos, como en la judicial) por los mismos órganos. La necesidad, pues, de una articulación positiva, de una coordinación entre las normas de las dos esferas es, justamente, lo propio del círculo de encuadramiento, como está implícito en el propio concepto constitucional de bases».
} 
de la ley autonómica ${ }^{73}$; sin embargo, también hay que decir que, sin previsión legal, el TC ha establecido una modalidad de jurisprudencia meramente interpretativa, que hoy es una práctica habitual, y también otra doctrina completa sobre inconstitucionalidad mediata o indirecta de las normas autonómicas por contradecir las normas básicas ${ }^{74}$. A fin de cuentas, la Sentencia del TC que decretase la prevalencia del derecho del Estado quedaría integrada en este tipo de pronunciamientos en los que el efecto desplazamiento de la cláusula de prevalencia se traduce en la declaración de inconstitucionalidad sobrevenida de la norma autonómica.

La cláusula de prevalencia es el corolario de las bases normativas del Estado: no concede un valor superior a la legislación del Estado, pero ejerce un efecto desplazamiento, para el supuesto de modificaciones o nuevas regulaciones de condiciones básicas que entre en conflicto con previa legislación autonómica de desarrollo, que se verá desplazada en todo aquello que no pueda compatibilizarse con las nuevas bases, por resultar imposible una aplicación conjunta de ambas normativas. Éste es el verdadero objeto y sentido de la cláusula de prevalencia sobre la que, coincidiendo, curiosamente, con una corriente doctrinal y una práctica judicial favorable a la aplicación de la cláusula por los Tribunales ordinarios (STS de 19 de septiembre de 2.006) - como una parte de su competencia para seleccionar la norma aplicable al caso- - se observa un cambio en la doctrina constitucional favorable a su aplicación en materia de concurrencia legislativa (leyes de bases versus desarrollo normativo por las CCA); sin embargo, no es capaz de establecer una sentencia que se atenga al efecto desplazamiento; por el contrario, cuando asume que

\footnotetext{
${ }^{73}$ STC 1/2003 F 9: «Partiendo de estas consideraciones, debemos concluir que la disconformidad sobrevenida de las disposiciones autonómicas cuestionadas con las nuevas bases en materia de régimen estatutario de los funcionarios públicos adoptadas por el legislador estatal (con respeto de la doble dimensión, formal y material, del concepto constitucional de bases) tras el momento de promulgación de la Ley 5/1995 y el de su impugnación ante este Tribunal determina la actual inconstitucionalidad de aquellas disposiciones originariamente respetuosas del orden constitucional de distribución de competencias, pues debe recordarse que es doctrina de este Tribunal que la normativa estatal a tener en cuenta como elemento de referencia para el enjuiciamiento de las normas autonómicas en procesos constitucionales en los que se controla la eventual existencia de excesos competenciales ha de ser la vigente en el momento de adoptarse la decisión por parte de este Tribunal sobre la regularidad constitucional de los preceptos recurridos, SSTC 28/1997, de 13 de febrero, F. 2; y 170/1989, de 19 de octubre.»

74 «Pero la intervención de este Tribunal, cuando fuera impetrada por quienes están legitimados para hacerlo, se limitaría a declarar la inconstitucionalidad sobrevenida de la norma autonómica, que no fuese compatible con las nuevas bases estatales, pero no su nulidad. La premisa del artículo 39.1 de nuestra Ley Orgánica consiste en una contradicción directa entre una ley y la Constitución. Sin embargo, el supuesto de «inconstitucionalidad mediata o indirecta» de una ley autonómica por contradecir la legislación básica sobrevenida sería uno de esos casos en que quiebra la conexión entre inconstitucionalidad y nulidad, casos detectados por este Tribunal en varias Sentencias (SSTC 45/1989, de 20 de febrero, FJ 11; 96/1996, de 30 de mayo, FJ 23; 195/1998, de 1 de octubre, FJ 5), y que revisten una singular importancia en el ordenamiento complejo propio del Estado de las autonomías, como muestran los numerosos fallos en que la contradicción de leyes con el orden constitucional de competencias no ha dado lugar a la nulidad de las normas estatales, sino a la delimitación de su ámbito de vigencia (por ejemplo, SSTC 95/1984, de 18 de octubre, FF.JJ. 3 y 4 y fallo; 125/1984, de 20 de diciembre, FJ 2 y fallo; 53/1988, de 24 de marzo, FJ 1 y fallo; 227/1988, de 29 de noviembre, FJ 23 y fallo; 133/1990, de 19 de julio, FJ 10 y fallo; 233/1999, de 16 de diciembre, FJ 38 y fallo; 206/2001, de 22 de octubre, FF.JJ. 9-12 y 21, y fallo; 95/2002, de 25 de abril, FJ 19 y fallo).
} 
una modificación de las bases o de las condiciones básicas implica una disconformidad sobrevenida de la ley autonómica previa, termina por declarar su inconstitucionalidad, advirtiendo, ahora sí expresamente, sobre la improcedencia de la aplicación de la cláusula de prevalencia por los tribunales ordinarios que, por el momento, se limitan a su aplicación cuando existe doctrina constitucional previa.

Podemos concluir que la discusión no está cerrada y que sigue la controversia doctrinal, sin que esté resuelta la incorporación de los efectos de la prevalencia a la de Sentencia de inconstitucionalidad ni las posibilidades y los requisitos de su aplicación por tribunales ordinarios. Sin olvidar las redacciones de los nuevos estatutos que, para evitar su aplicación, asumen como exclusivas, ahora también como excluyentes y preferentes, todas las competencias de desarrollo normativo, artículos 111 a 113 del nuevo Estatuto de Autonomía para Cataluña, prescribiendo expresamente la aplicación preferente del Derecho de Cataluña. 